\title{
A PHENOMENOLOGICAL PERSPECTIVE ON VALUE CREATION AND PERCEPTION IN MUSIC INFORMATION SYSTEMS
}

\author{
Belinda Moloney ${ }^{1,2}$, Jacob Cyulski ${ }^{1,3}$ and Lemai Nguyen ${ }^{1,3}$ \\ ${ }^{1} \mathrm{Dr}$. \\ ${ }^{2}$ Deakin University, Geelong, Victoria, Australia \\ ${ }^{3}$ Deakin University, Burwood, Victoria, Australia
}

\begin{abstract}
When referring to the value that IS adds to organisations, we often refer to monetary value and rarely are perspectives extended beyond monetary significance. Research suggests that value of a product or service is often perceived subjectively by an individual. A sound understanding of value and its perception by IS stakeholders will be beneficial in developing information systems that create value for an organisation, which is well-received by their users. This paper therefore discusses the concepts of value and its importance in IS. The paper focuses on a challenge to studying value in IS - although value manifests in properties of an information system, it can only be experienced and perceived subjectively through sense, experience and judgement of the system stakeholders. To address this challenge, the paper suggests adopting a phenomenological approach to studying value as perceived by different stakeholders involved in the development and application of information systems.
\end{abstract}

\section{KEYWORDS}

Information Systems, Phenomenology, Perception, Value

\section{INTRODUCTION}

Despite a growing number of researchers exploring the value of innovative information and communication technologies (ICT), only a few studies exist which take a philosophical perspective on the techno-organisational aspects of value, its perception and creation, all of which may affect or be affected by the deployment of new technologies. Regardless of a business' nature, industry or objectives, the term 'value' often represents the economic measure of success attained by business for its employees and clients, perceived and received by these employees and clients. However, other facets of value measurement and its perception by the information system stakeholders are equally important.

The research area of value perception encompasses areas of psychology, social sciences and philosophical inquiry, which all embrace different approaches to studying and understanding human perception of values. Yet it is within IS that the perception of value is rarely examined. This is mainly due to the traditional approach to assessing performance of information technology (hardware and software), which can be readily quantifiably measured and understood. Amongst information systems research, the quantification of IS value, as evidenced in evaluation and measurement of IS success, has also received much attention (Boehm, 2006; Carlson \& McNurlin, 1992; Duggan \& Reichgelt, 2006). Such understanding of issues and measuring instruments is not so apparent in studying the personal, organisational and socio-cultural dimensions of information systems.

Unlike the concept of value measurement, the essence of value is considerably more difficult to capture and it is grounded predominantly in the qualitative research tradition. The qualitative determination of value stems largely from the perception of value and the axiological 'goodness' of an outcome as it affects key stakeholders (Lemos, 1995). Information systems are no exception to this rule; for example, in addition to IS economic values (ROI), Boehm (2006) also identifies many socio-organisational benefits, such as business predictability and customer satisfaction. A deeper understanding of value is therefore required to reflect complex personal, organisational and socio-cultural dimensions of information systems. As this research 
focuses on the understanding the perception of techno-organisational value in IS, we have taken a phenomenological perspective, which allows us to explore the IS stakeholders' subjective world, their lived experience with techno-organisational change, and their emotional responses to the introduction of information systems (Moustakas, 1994).

Phenomenology has been found to be highly applicable to the study of IS and IS-adopting stakeholder perceptions (Boland, 1985; Moreno, 2002; Sarkar \& Cybulski, 2004). The main strength of phenomenology comes from its ability to deal with issues of psychological influences - such as memory, experience and perception - on human activity in IS; phenomenology "seeks to understand human experiences... generating broad and general research questions" which are suited to research areas requiring a "descriptive, synthesized narrative of the phenomenon under study" (Smith \& Davis, 2003, p. 115).

Further in the paper, we will provide examples of 'value' as drawn from a study of information systems created in support of development, distribution and 'experience' of music products. This study identifies the perceptions of various stakeholders within the Australian music industry, ranging from artist, sound engineer, promoter, distributor to event manager. The study gives insight into and suggests a further exploration into the concept of value and value chain in IS-enabled music production and distribution. In the subsequent sections, we will refer to this application domain simply as 'music IS'.

\section{MUSIC INFORMATION SYSTEMS}

Music is partaken "for the sake of amusement and relaxation" as it "contributes to the enjoyment of leisure and mental cultivation," (Hofstadter \& Kuhns, 1964, p. 131) a description which reinforces the significance of music in culture and traditions. When looking at music as an experience, it is important to understand the nature of the music industry as it exists as a vessel and conveyer of value along the value chain and its intermediaries, in order to expose the perspectives of these intermediaries and their roles as value facilitators. According to Moloney (2005) and Fridey, Cybulski, and Nguyen (2010), the music value chain as an information system, has transformed in recent years, with the introduction of online distribution and artists adopting a self-directed, self-funded and self-distributed approach towards music production (see Figure 1).

\section{Traditional Value Chain Disintermediated Digital Value Chain}
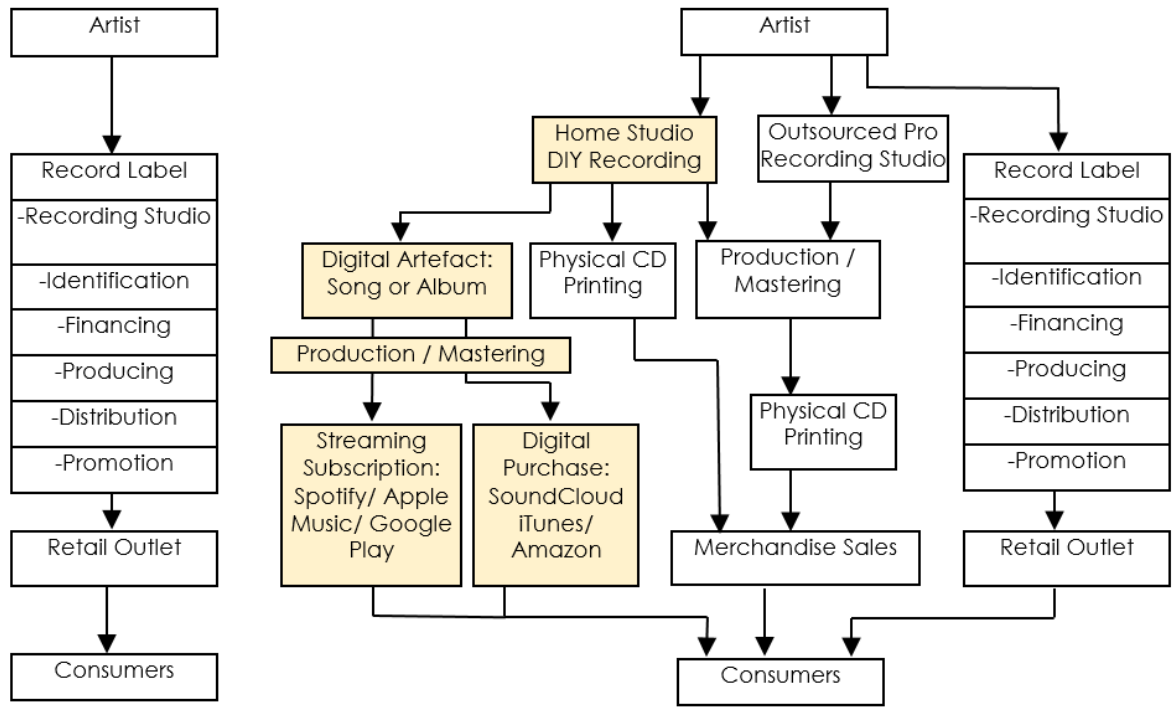

Figure 1. Traditional vs Disintermediated Music Industry Value Chain (Adapted from: Moloney, 2005, and Fridey et. al. 2010) 
Changes in the music value chains were found to include direct distribution to consumers, reduction in the number of intermediating parties, increased online music collaboration and artist entrepreneurialism. It is clear from Figure 1 that as music innovation and delivery technology advanced, the industry has 'disintermediated' and the options available to artists have increased. As Reddy and Reddy (2002)) explained, the initial focus of music innovation was on the consumer, the later advances in the use of the Internet (Hampe \& Schwabe, 2003), mobile and wireless technologies had a significant impact on music industry, its profitability and distribution mechanisms.

These more recent information systems-centric benefits have effectively altered the music value chain, helping consumers to listen to music in electronic forms, such as procurement of digital music files, and subscription-based streaming procurement via the Internet (Spotify, Pandora, YouTube); thus, bypassing traditional retailers and their 'bricks and mortar' distribution channels (Reddy \& Reddy, 2002). In the face of these drastic changes to music and its distribution, the question arises whether or not the new IS technology has altered the traditionally held value of music as a physical product. Peppard and colleagues presented the notion of IS facilitating the delivery of value to business and consumers, where "technology is merely a part of the value creation process" (2000, p. 292). So what constitutes this value?

\section{VALUE PERCEPTION}

Value in general terms extends to "conceptions of reality existing under ideal phases such as truth, beauty and goodness" (Dibblee, 1924, p.16), since an individual's determination of value "depends completely on customer's expectations or their perception of value" (Trischler, 1996, p.7). Notably, an everyday concept of value is often rather a qualitative expression of the goodness of the value as reflected by the perception of the stakeholder. We contend that the concept of value in Music IS cannot be readily defined unless the context and nature of the 'value' in question is first established.

In order to create values through information systems, IS management need to understand all aspects of values. Value is a relative notion and is subjectively defined in the eye of the beholder. In IS, various stakeholders - including developers, management, users and customers - maintain their own ideas of value regarding price, product, service and quality standards (Dodds, 2003). Within the realms of music IS, this monetary value could be further realised with the introduction of online music streaming network, and a resulting reduction in the fiscal expense of a music experience when juxtaposed with the cost of a music product purchase.

\subsection{Value and Music IS}

To follow on from the aforementioned IS music example, non-monetary value within an IS could be exemplified by an online music network providing the accessibility of rare or international music to remote areas, where retailers are unable to make an in-store purchase of physical music products. This accessibility and convenience holds a value to which stakeholders cannot consistently assign a quantitative or monetary equivalent of value, since this differs in each person's perception in accordance to their moral standing, and their understanding of a product's 'goodness' (Vilkka, 1984). To create or add values through information systems, it is important to identify different attributes of value of the systems in the context of use.

Ultimately, extrinsic value encapsulates the notion of externally added elements that enhance one's perception of value of the said object to an individual, which may include various attributes of value that are developed through human perception and circumstance. For example, the extrinsic value of a music track could be perceived within the name (brand) of the artist, the perceived authenticity of the artist (Bridson, Evans, Varman, Volkov, \& McDonald, 2014), the producer's name or record label, the music album artwork or format (Harvey, 2017), the video-clip, the web site from which the track could be downloaded, concert tour, fan club or the adverting campaign

In modern IS, such as online music IS, value is derived directly from IS-supported business activity such as the availability of new IS services (e.g. in lieu of music web sales), from the electronic inter-organizational transactions and interactions (e.g. payment associated with music sales), from IS-enabled flow of digital music products, from the IS-facilitated business visibility and its presence (e.g. via online advertising of 
music artists) and from the IS product and service availability to customers (e.g. from online stores and digital music subscription providers).

Further to this, Grey and Shi (2005) extend the notion of value for customers in general, to include factors such as quality, quantity, complexity, serviceability, obsolescence, and price, which impact upon the entire value chain of a business and the decision by a customer to purchase from a specific supplier (Grey \& Shi, 2005). As a result of this broadened understanding of value in IS and in business, the group of value creators in IS development and its subsequent business implementation expands to include not only direct IS project stakeholders, but also contents developers and copyright consultants, marketing and public relation specialists, media planner and strategists, creative and art directors, graphic designers, multimedia and interaction developers (Berry, 2006; Bridson et al., 2014; Fridey et al., 2010; Taylor, 1986).

Yet, as the notion of traditional product value transmutes due to the evolution of physical products and services into virtual products and their online delivery - particularly visible in Music IS - the concept of an e-value chain manifestly extends the aforementioned clarifications of value and music IS to encompass e-Business and e-Society elements, incorporating the Internet and IT to enhance the productivity of the conventional value chain, orchestrate more streamlined business processes, and increase value chain 'interconnectedness' (Grey \& Shi, 2005). Again, considering music IS and its shift to online subscription-based distribution, it is the extrinsic value of the music product that has changed in the most radical fashion.

On one hand, the consumer may no longer receive a physical $\mathrm{CD} /$ record and sleeve inclusive of extrinsically valuable art, marketing, and messages from the artist which are sacrificed in exchange for rapid, digital access (Fridey et al., 2010; Harvey, 2017). On the other hand, the music delivery vehicle, in the form of the music streaming subscription or artist website often becomes the rich source of information about the artist, including graphics and lyrics associated with music tracks are often embedded in the music files, and the new forms of previously non-existent direct communication between the music consumers and artists emerge via fan web sites and forums (Moloney, 2005). In both cases, the reduced/added value is rather subjectively experienced and perceived by different customers than determined with the intrinsic properties of the song, its melody and lyrics. Recent years have seen a resurgence of consumers buying music on a vinyl record format. Once thought to be a dated technology, is now reinvigorated as a novel reprise for nostalgic reasons, the rarity value embodied in a limited pressing, or as an indulgence to audiophiles whose prerequisite of purchasing high-quality audio includes the need for a music product to include the tactile qualities of a physical product such as album concepts, liner notes and artwork (Harvey, 2017).

The value of information systems may not manifest only in intrinsic properties of the system itself; there are extrinsic properties attribute to the system by involved stakeholders. While the discussion thus far explains the concepts of IS value and its value chain, we have not elucidated our findings on the mechanisms of value perception by different stakeholders and intermediaries along the value chain within this paper.

\section{PERCEPTION OF INFORMATION SYSTEMS VALUE: SENSE, EXPERIENCE AND JUDGEMENT}

Our individual value system depends largely upon our world-view, i.e. our ideology, knowledge, beliefs and perceptions (Vilkka, 1984). Such individual viewpoints are formed based on personal observations of the surrounding world and its external properties, which need to be internalised in the process of perception.

Perception is the way in which we, as individuals, "form the impressions of the qualitative and quantitative aspects of external objects, of their spatial positions and movements" (sense) (Dember \& Warm, 1979, p. 2). From these impressions we create a "likeness of the environment in our minds" (perception) (Goldstein, 2002, p. 3), which is highly subjective to each individual's interpretation. While many thinkers have explored the subject of knowledge and perception, it was Maurice Merleau-Ponty's phenomenological theory that provided insights into human perception from the vantage point of modern discoveries in cognitive science, psychology and sociology. He argued that the sensory perception is the basis of all experience, thought and knowledge, and in the case of music, our perceptions are subject to the perceptual alterations, which exist in the relationship between the physical object and the observer. 
Reflecting further on objects' sensory properties (such as music's sound, or the colour, shade and hardness of the CD or vinyl record cover), Merleau-Ponty (1962) questions the true nature of reality and its relationship with the human mind; he suggests that the data of perception cannot be simply deduced from the scientific laws but are instead a combination of sense data and human interpretation. In this way, an object's experiential and subjective quality (such as the music IS value) must be derived from the object's immediate sensory data and human subjective experience with the object. And so, the object's observed attributes cumulatively represent its quality to the observer (such as relaxing music or the music product's visually attractive design), the quality which is not possessed as a 'real part' of the perception but rather as its 'intentional part', and it holds some (previously experienced) significance to the perceiver (Merleau-Ponty, 1962, p. 16).

Perception of complex objects (such as music IS) commonly exhibits an elaborate structure (e.g. reflecting the music IS cost, interactivity, availability, quality of music or online accessibility). While experiential attributes of such a complex perception readily impress upon the observer (such as cost, interactivity or availability), others require the observer's judgement to identify the indirect 'hermetically sealed' qualities (such as music quality or accessibility). Merleau-Ponty (1962, pp. 37-38) introduced 'judgement' as "what sensation lacks to make perception possible" which relies on the conscious interpretation of sensory data to allow linking one's experience with perception, so that it could be understood by the observer and possibly by others as well.

Sense, experience and judgement are three important elements of the Merleau-Ponty's philosophy of perception, which we adopt to understand and describe the notion of IS value. Considering that our research primarily concerns the value of music IS, its processes and its products; the relevant aspects of involved cognitive functions must necessarily involve audio-visual cues (perception of music and the associated artwork, system interfaces, etc.) and motor-sensory responses (information system interaction). The subjective value perception and the stakeholder satisfaction with the innovative music IS (functionality, speed, effectiveness, etc.) need to be grounded in the sensory aspects of music and accompanying products (music, media, touch and feel) and their perceived quality (accessibility, usability, ergonomics). Interestingly, as our minds become accustomed to using innovative technologies, our "perception becomes an 'interpretation' of our senses, and our sense of value determines the judgement of value through our experience with new technology. Another factor perceived as important by consumers of creative products is 'authenticity' as the perceived outward manifestation of an artist who has not effectively 'sold out' by commercialising their approach to developing a music product, and thus losing their previously perceived value in the eyes of critical consumers (Bridson et al., 2014).

Amongst the notions of perceptions and individuals' opinion of value, there remain questions as to how sense, experience and judgment influence the perception of value and how decisions are made based upon such perception. Their different perceptions of value need to be explored in order to successfully create value to business through information systems.

\section{APPLYING PHENOMENOLOGICAL INQUIRY TOWARDS UNDERSTANDING INFORMATION SYSTEMS VALUE}

In the previous sections, we have argued about the importance and challenge in studying value in IS. While value needs to be understood, it is difficult to study value as it may not fully manifest in properties of an object itself; instead value can only be perceived through sense, experience and judgement. The music IS examples demonstrate that contemporary IS values are perceived in a highly subjective fashion, their characterisation is subject to immediate context and direct human experience, and as such they may be difficult to observe, objectively measure and ultimately research. Therefore, in order to study value, researchers need to seek the capture of feelings, experiences and judgements by involved stakeholders rather than studying the properties of IS in the system itself. Consequently, the selection of appropriate methods of inquiry to study the perception of IS value is crucial. In this section, we discuss and suggest using phenomenology to studying value in IS.

Phenomenology was proposed by Edmund Husserl (1965) as a research approach to studying the meaning of a phenomenon through emphasising on the essence of human experience. The use of phenomenology is often recommended for studying socio-cognitive phenomena, where there is a need for the capture and 
refinement of rich qualitative data, subject to personal views and opinions, and which calls upon interpretative data analysis (Denzin \& Lincoln, 2005). In IS, phenomenology has been described by the research community as a valid and relevant research approach for studying the meaning of a phenomenon (the development and use of IS) with a focus on human experience, feelings and concerns (Boland, 1985). Phenomenology has increasingly been adopted within the IS discipline with Boland (1985)) strongly advocating phenomenology as a preferred interpretive research approach in IS, alongside Fridey et al. (2010), Mingers (2001), Sarkar and Cybulski (2004) and Moreno (2002) who argue the relevance of phenomenology in IS research.

Phenomenology is relevant in studying value as perceived by various stakeholders involved in the development and application of an information system. Researchers seek to understand meaning and essence of a phenomenon that is locked in human memory as exposed to lived experience by research participants (so called co-researchers in phenomenology), by extracting long interviews, undertaking data analysis and synthesising findings (Moustakas, 1994). When studying value, the phenomenon under study is the perception of value of an information system, the co-researchers are the various involved stakeholders. Data collection and analysis can be designed to focus on the feelings, experiences and judgement of the information system under study. Subjective perceptions of value can be drawn based on reflection on the co-researchers' own feelings, experiences and judgement of information system.

Further, phenomenology can be useful in studying value of information systems in the fast changing social and business context. In a Music IS context, this implies that new viewpoints (value perceptions) need to be adopted forcibly, constantly and rapidly by all those involved in the creation and use of information systems. Hence, when looking at the concepts of value and perception through the lens of phenomenology, the resulting personal viewpoints will provide an ever-changing picture of the very phenomenon of IS value.

Phenomenology also provides a rigorous, valid framework for interpretive research (Moustakas, 1994). Similar to other qualitative interpretive research approaches, phenomenology researchers' may already have preconceived notion of IS value which would (often unwittingly) interfere with the research process. According to Moustakas (1994), during epoche, an early stage of the phenomenology research process, the researchers identify their own knowledge and preconceptions of the investigated phenomena, and to recognise and consider their own bias towards the subject matter. Hence, the researcher can "set aside preconceptions to best understand the phenomenon as experienced by participants" (Creswell, 1998, p. 31) after gaining insight as to how their biases may affect research outcomes.

In terms of the research process, a phenomenological study of IS value would follow the circle of hermeneutic understanding. Completing a full cycle of data collection, analysis and reflection; each hermeneutic cycle builds upon the learning from the preceding cycle (Gadamer, 1976). Moustakas (1994)) describes each hermeneutic cycle in terms of four stages including epoche (to set aside the researcher's biases and preconceptions), phenomenological reduction (the construction of stories of feelings, experiences and judgement by co-researchers), imaginative variation (the construction of the meaning of the stories), and synthesis of meanings found in individual stories.

For example, our study adopted a phenomenological approach to build upon extant research and study the value creation and its perception within music information systems. The adopted phenomenological approach involves cyclical interviews with numerous IS stakeholders along the music distribution value chain, including musicians, sound engineers, web masters, event organisers, distributors, retailers and music consumers. A series of long interviews are conducted to provide narratives full of rich qualitative data, which are analysed for thematic similarities and differences of opinions and views on IS value. Understandings of values are being built upon and refined through hermeneutic cycles, each cycle proceedings through four stages of epoche, reduction, variation, and synthesis. Following an analysis approach, described by Mallery and Hurwitz (1986), insights that are common (themes) across hermeneutic cycles are subsequently structured and analysed based on the impact on the current understanding of the IS value, and the most important insights subsequently synthesised.

Intriguingly, music and IS value seem to fully align with the aims of phenomenology which is concerned with perceptions, judgements and feelings which are all essential in the process of an individual's assessment of value. Phenomenology is suggested as a useful research method to construct an information system's value as perceived by stakeholders involved in the value creation chain for creative products. 


\section{CONCLUSION}

This paper has revealed a number of connections between information systems, values and perceptions. Up until now, the perception of value within the information systems discipline has been poorly understood, often confused with the representation of success or economic measure, and hence exceptionally difficult to accurately determine. The paper introduced the concept of value as a highly subjective notion, much broader than monetary worth, and which is undoubtedly linked to one's perception and value system. The paper discusses various aspects that comprise an individual's perception about value of an object, including sense, experience and judgement. Through the discussion of the concept of value and different aspects of value perceptions, the paper presents a challenge to the IS research community: how best to study value which is a subject of direct experience and perception? To address the challenge, the paper suggests phenomenology as a method to understand the values that exist amongst IS stakeholders.

A rich understanding of value, as perceived by different stakeholders, can enhance IS development methods to deliver new information systems which create value to business. For example, Boehm's (2006) valued-based requirements engineering approach includes identification of stakeholders, determination of their value propositions, negotiation and prioritisation of values. Boehm (2006) suggests integration of a win-win position within the identification and prioritisation of values, decision theory (to support decision making), dependency theory (to understand how dependencies influence value realisation) and control theory (to manage change and value realisation). While such an approach has potential benefits to identify and deliver values to business, their current notion of value is largely based on quantitatively measurable values. There has not been clear guide to understand intangible values, such as those perceived by individuals experiencing music products whose delivery is enabled by information systems. Our approach to studying values has potential benefits of gaining a rich understanding of values grounded in the domain of essence: perceptions and experiences by relevant stakeholders. Such an understanding can be integrated within Boehm's value-based requirements engineering and subsequent phases of value-based systems development.

Business innovation is no longer in the pursuit of technological breakthroughs but rather in the pursuit of added value for clients and other stakeholders. Since creation of perceived value is crucial to innovation, it is important to understand and assess value perceptions from different stakeholders' perspectives along the music value chain. Therefore, a rich understanding of what is perceived as value by different stakeholder can be useful to managers, stakeholders or decision makers attempting to implement innovative technology solutions, or possibly by organisations trying to retain value within their product or service. Phenomenology is a relevant and useful method of inquiry in pursuing this objective within the information systems discipline.

\section{REFERENCES}

Berry, J. (2006, September 12-14, 2006). Music Industry Value Chains in the Early 21st Century. Paper presented at the British Academy of Management: Building International Communities Through Collaboration, Belfast, Ireland.

Boehm, B. W. (2006). Value-Based Software Engineering: Overview and Agenda. In S. Biffl \& A. Aurum (Eds.), Value-Based Software Engineering (pp. 3-14). Berlin, Germany: Springer.

Boland, R. J., Jr. (1985). Phenomenology: A Preferred Approach to Research on Information Systems. In E. Mumford (Ed.), Research Methods in Information Systems (pp. 181-190). North-Holland: Elsevier Science Publishers.

Bridson, K., Evans, J., Varman, R., Volkov, M., \& McDonald, S. (2014). Questioning worth: selling out in the music industry. European Journal of Marketing, 51(9/10), 1650-1668. doi:https://doi.org/10.1108/EJM-06-2015-0391

Carlson, W. M., \& McNurlin, B. C. (1992). Measuring the Value of Information Systems. Retrieved from Rockville, MD, USA:

Creswell, J. W. (1998). Qualitative Inquiry and Research Design: Choosing Among Five Traditions. Thousand Oaks, California, USA: SAGE Publications.

Dember, W., N., \& Warm, J., S. (1979). Psychology of Perception (2nd ed.). New York, USA: Holt, Rinehart and Winston.

Denzin, N. K., \& Lincoln, Y. S. (Eds.). (2005). The Sage Handbook of Qualitative Research (3rd ed.). Thousand Oaks, California, USA: SAGE Publications. 
Dibblee, G. B. (1924). The Psychological Theory of Value. London, England: Constable and Company, The Whitefriars Press.

Dodds, B. (2003). Managing Customer Value. Lanham, Maryland, USA: University Press of America.

Duggan, E. W., \& Reichgelt, H. (Eds.). (2006). Measuring Information Systems Delivery Quality. Hershey, PA, USA: Idea Group Publishing.

Fridey, B., Cybulski, J., \& Nguyen, L. (2010). Transforming value perception in music information systems. Paper presented at the AMCIS 2010 Proceedings, Lima, Peru, South America.

Gadamer, H.-G. (1976). Philosophical Hermeneutics (D. E. Linge, Trans.). Berkley, California, USA: University of California Press.

Goldstein, E. B. (2002). Sensation and Perception (6th ed.). Pacific Grove, California, USA: Wadsworth Group, Thomson Learning.

Grey, W., \& Shi, D. (2005). Enterprise Risk Management: A Value Chain Perspective. In A. Labbi (Ed.), Handbook of Integrated Risk Management for E-Business: Measuring, Modeling and Managing Risk. Boca Raton, Florida, USA: J. Ross Publications.

Hampe, J. F., \& Schwabe, G. (2003). Enhancing Mobile Commerce: Instant Music Purchasing Over the Air. In K. V. Anderson, S. Elliot, \& P. M. C. Swatman (Eds.), Seeking Success in E-Business (pp. S. 107-130). Dordrecht, Germany: Kluwer Academic Publishers.

Harvey, E. (2017). Siding with vinyl: Record Store Day and the branding of independent music. International Journal of Cultural Studies, 20(6), 585-602. doi:10.1177/1367877915582105

Hofstadter, A., \& Kuhns, R. (Eds.). (1964). Philosophies of Art and Beauty (Modern Library Edition ed.). New York, NY, USA: The Modern Library.

Husserl, E. (1965). Phenomenology and the Crisis of Philosophy (Q. Laver, Trans.). New York, USA: Harper and Row Publishers.

Lemos, R., M. (1995). The Nature of Value: Axiological Investigations. Gainsville, Florida, USA: University Press of Florida.

Mallery, J. C., \& Hurwitz, R. (1986). Hermeneutics: From Textual Explication to Computer Understanding? Massachusetts, USA: Massachusetts Institute of Technology.

Merleau-Ponty, M. (1962). Phenomenology of Perception (C. Smith, Trans. English Translation ed.). New Jersey, USA: Humanities Press, Routledge and Kegan Paul.

Mingers, J. (2001). Embodying Information Systems: The Contribution of Phenomenology. Information and Organization, 11, 103-128.

Moloney, B. J. (2005, Nov 30 - Dec 2, 2005). Investigation of the Value Chain for Creative Products: A Phenomenological Study of the Perceptions of Music Intermediaries. Paper presented at the Australasian Conference on Information Systems, Social IT, Sydney, NSW, Australia.

Moreno, V., Jr. (2002). Validity Issues in Phenomenological Research: Bridging Theory and Practice in a Study of IT-Driven Radical Organizational Change. Paper presented at the Eighth Americas Conference on Information Systems, Dallas, Texas, USA.

Moustakas, C. E. (1994). Phenomenological Research Methods. Thousand Oaks, California, USA: SAGE Publications.

Peppard, J., Lambert, R., \& Edwards, C. (2000). Whose Job is it Anyway? Organisational Information Competencies for Value Creation. Information Systems Journal, 10, 291-322.

Reddy, R., \& Reddy, S. (2002). Extracting Value from the Supply Chain with Mobile Technologies. Journal of Internet Commerce, 1(3), 65-80.

Sarkar, P., \& Cybulski, J. L. (2004). Evaluation of Phenomenological Findings in IS Research: A Study in Developing Web-Based IS. Paper presented at the ECIS 2004 Conference, Turku, Finland.

Smith, R. A., \& Davis, S. F. (2003). The Changing Face of Research Methods. In S. F. Davis (Ed.), Handbook of Research Methods in Experimental Psychology (1st ed.). Oxford, England: Blackwell Publishing.

Taylor, P. W. (1986). Respect for Nature: A Theory of Environmental Ethics. Princeton, New Jersey, USA: Princeton University Press.

Trischler, W. E. (1996). Understanding and Applying Value-Added Assessment: Eliminating Business Process Waste. Retrieved from Milwaukee, Wisconsin, USA:

Vilkka, L. (1984). The Intrinsic Value of Nature (Vol. 59). Amsterdam, The Netherlands: Rodopi B.V. 